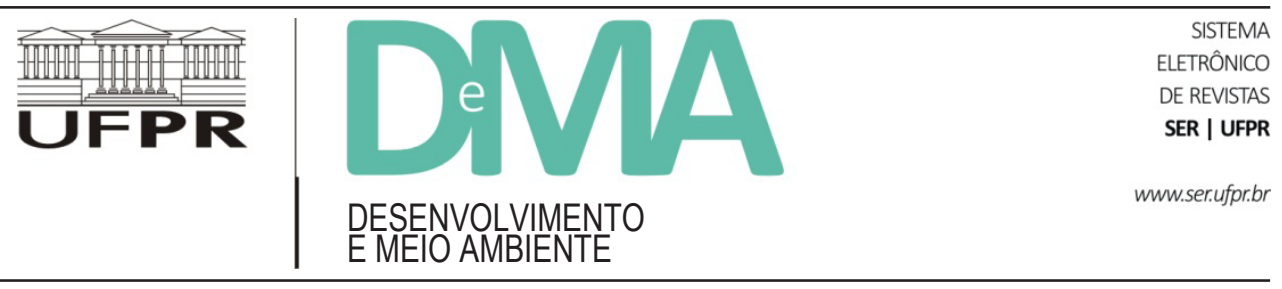

\title{
O processo de implementação do Projeto Orla em Itapema, Santa Catarina - Brasil
}

\section{The Implementation Process of Projeto Orla in Itapema, Santa Catarina - Brazil}

\author{
Maria Emília Martins da SILVA ${ }^{1 *}$, Eduardo Juan SORIANO-SIERRA² \\ ${ }^{1}$ Instituto Federal Catarinense (IFC) - Campus Avançado Sombrio, Sombrio, SC, Brasil. \\ ${ }^{2}$ Núcleo de Estudos do Mar (NEMAR), Universidade Federal de Santa Catarina (UFSC), Florianópolis, SC, Brasil. \\ *E-mail de contato: emilia@ifc-sombrio.edu.br
}

Artigo recebido em 23 de junho de 2015, versão final aceita em 1 de março de 2016.

RESUMO: A gestão da zona costeira brasileira tem sido cada vez mais valorizada devido às suas características físicas, biológicas e paisagísticas e por apresentar potencialidades para o desenvolvimento socioeconômico das cidades. Contudo, verifica-se ao longo dos anos uma série de conflitos e interesses múltiplos referentes aos bens da União, em especial quanto aos usos da orla marítima. No intuito de disciplinar o uso e a ocupação da orla, o Ministério do Meio Ambiente (MMA) e a Secretaria do Patrimônio da União (SPU) criaram o Projeto de Gestão Integrada da Orla Marítima (Projeto Orla). Neste contexto, o município de Itapema, litoral norte do Estado de Santa Catarina, iniciou o processo de implementação do Projeto Orla em 2006, com resultados consolidados. O estudo descreve esse processo segundo a atuação da gestão pública municipal. Os métodos adotados na pesquisa estão embasados no paradigma interpretativista, por meio do estudo de caso. Seu aporte principal se desenvolveu por meio da técnica de entrevista semiestruturada com três representantes da gestão pública municipal e um stakeholder da SPU do Estado de Santa Catarina. Os resultados demonstraram que o poder executivo municipal não seguiu todas as diretrizes mandatórias dos órgãos responsáveis pelo Projeto Orla, consideradas fundamentais para fiscalização, manutenção e gestão da orla após as etapas de intervenção, como, por exemplo, a continuidade do Comitê Gestor da Orla. Ainda assim, o município obteve apoio técnico e recursos para obras de revitalização e aquisição de estruturas urbanísticas no espaço da orla, com apreciação positiva da comunidade local.

Palavras-chave: gestão ambiental; zona costeira; sustentabilidade; cidades costeiras.

ABSTRACT: The Brazilian coastal zone management has been increasingly appreciated due to physical, biological and landscape features, besides being the birthplace of terrestrial and marine biodiversity and socioeconomic development. However, over the years a series of conflicts and multiple interests to Federal assets were found, in particular related to the use of the seafront. In order to regulate the use and occupation of the seafront, the Ministry of Environment (MMA) and the Department of Heritage Union (SPU) created the Orla Project. In this context, the city of Itapema, located at northern coast of Santa Catarina State, started the process of 
implementation of the Orla Project in 2006, with some consolidated results. Therefore, this study describes this process from the perspective of public management. The methods used are based on the interpretive paradigm. The main contribution was developed by the technique of semi-structured interviews with three representatives of public management and a SPU stakeholder from the state of Santa Catarina. The results showed that the municipal executive did not follow all the guidelines mandatory for the Orla Project, considered fundamental for monitoring, maintenance and management of the waterfront following the steps of intervention. Still, the city obtained technical support and resources for revitalization works and acquisition of urban structures on the waterfront, with positive appreciation of the local community.

Keywords: environmental management; coastal zone; sustainability; coastal cities.

\section{Introdução}

A sustentabilidade tem tido um papel proeminente nas discussões das organizações públicas e privadas nas últimas décadas, com inclusões de projetos e ações preventivas e corretivas, cada qual buscando atender suas necessidades mais urgentes, conjugando-se aos seus padrões de gestão (Claro et al., 2008; Schaltegger, 2011; Starik \& Kanashiro, 2013). O paradigma, cunhado por Maurice Strong e Ignacy Sachs na década de 1970, tentava buscar soluções para os problemas ambientais e sociais gerados pela degradação ambiental e pelo crescimento populacional, que já apresentava perspectivas quantitativas desastrosas numa esfera global (Sachs, 2008; Seiffert, 2011).

Percebe-se atualmente que as organizações públicas e privadas estão atentas às necessidades da sociedade e às alterações antrópicas ao ambiente, buscando, sobretudo, a regeneração urbana, espacial e a reinvenção das cidades, com projetos de revitalização e reorganização do espaço (Leite $\&$ Awad, 2012). Frente a esse cenário, toma-se por reflexão a gestão das cidades costeiras, pois esse espaço territorial constitui o cerne de grande parte da população mundial, a qual supõe uma série de interesses e conflitos sociais, econômicos e ambientais para o espaço da orla marítima (Moraes, 2007; Leite \& Awad, 2012; Scherer, 2013).
Segundo Brorström (2015), as cidades terão de enfrentar grandes desafios no futuro, tais como o crescimento da urbanização, a exclusão social e as alterações climáticas.

Na visão de Nakano (2006), as cidades costeiras expandem-se vertical e horizontalmente, inclusive em áreas vulneráveis, constituindo ao longo do tempo espaço de adensamento populacional e de atração de fluxos povoadores. Tais eventos exercem forte pressão sobre os recursos naturais, proveniente de inúmeras atividades produtivas, causando impactos permanentes e irreversíveis para o ambiente natural e para o bem-estar das comunidades autóctones (Van Vuren et al., 2004; Nakano, 2006; Moraes, 2007; Cardoso Junior et al., 2012).

Tem-se observado nos balneários, nas últimas décadas, a construção e a ampliação de equipamentos turístico-hoteleiros e condomínios de luxo vinculados a uma política imobiliária de crescimento ilimitado, levando as cidades costeiras a um consumo excessivo de recursos naturais, as quais não têm condições de suporte (Silva \& Ferreira, 2011; Cardoso Junior et al., 2012; Silva \& Soriano-Sierra, 2013; Lima, 2013). Esse ritmo de ocupação desconsidera muitas vezes as necessidades e os desejos da comunidade local, afetando, por sua vez, ambientes significativos de proteção ambiental, como os manguezais, as dunas e sua vegetação fixadora, as restingas, os recifes de co- 
rais, entre outros considerados de alta fragilidade e produtividade biológica (Ministério do Turismo, 2010). Ademais, devido ao aumento da população em períodos sazonais, ao uso excessivo do solo e à alienação ou desobediência aos limites de construção na faixa costeira permitidos por lei, a gestão integrada da zona costeira - aliada à participação da comunidade na atualização do plano diretor - torna-se necessidade urgente para a gestão sustentável do território (Francia, 2012; Lanza \& Randazzo, 2013; Silva \& Soriano-Sierra, 2013), mas que nem sempre se efetiva.

No Brasil, o principal instrumento de planejamento da Política Nacional de Recursos do Mar e da Política Nacional de Meio Ambiente é o Plano Nacional de Gerenciamento Costeiro (PNGC), instituído pela Lei n. 7.661 de 1988, que apresenta como um de seus principais objetivos o ordenamento dos usos na zona costeira visando à conservação e à proteção dos recursos costeiros e marinhos (Brasil, 1988; Conselho Nacional do Meio Ambiente, 2003). Emanado do PNGC de 1997 e do Plano de Ação Federal para a Zona Costeira (PAF-ZC) de 2005, ambos aprovados pela Comissão Interministerial para os Recursos do Mar (Pinto, 2012), o Ministério do Meio Ambiente (MMA) e a Secretaria do Patrimônio da União (SPU) instituíram, em 2001, o Projeto de Gestão Integrada da Orla Marítima (Projeto Orla). Seu objetivo é implementar uma política nacional que articule as ações patrimoniais e ambientais, por meio de uma gestão descentralizada entre a União, Estados, Municípios e a sociedade civil organizada, conjugando-se ao planejamento participativo sobre o uso e ocupação do espaço costeiro brasileiro (Brasil, 2004). Moraes \& Zamboni (2004) ressaltam que a metodologia do Projeto Orla é inovadora e prioriza a conservação dos recursos ambientais, sociais e a qualidade paisagística da orla brasileira em suas cidades costeiras.
O Projeto Orla completou quatorze anos de criação em 2015, envolvendo 17 estados costeiros e aproximadamente 330 municípios defrontantes (Silva, 2013). Contudo, ainda que sua estrutura apresente resultados consistentes, uma metodologia eficiente e o alcance dos objetivos do PNGC, a maior problemática situa-se na gestão da orla e na deficiência de ações coordenadas e sistêmicas dos órgãos envolvidos, uma vez que a fiscalização e manutenção dos projetos de intervenção, especialmente em nível local, ainda se encontram aquém do esperado (Cardoso Junior et al., 2012; Silva, 2013).

$\mathrm{Na}$ zona costeira do Estado de Santa Catarina, diversos municípios iniciaram o processo de implementação do Projeto Orla, em parceria com a Coordenação Nacional e Estadual (GERCO/SC). Dentre esses, o município de Itapema, localizado no litoral centro-norte do Estado, aderiu ao processo em 2007, tendo parte de seus resultados consolidados na implantação do "Parque Linear Calçadão", no bairro Meia Praia, em dezembro de 2012, sendo considerado de interesse para um estudo de caso como prática replicável para outras cidades costeiras.

Justifica-se a eleição pela cidade de Itapema devido ao seu histórico de crescimento urbano e adensamento territorial, com predominância no bairro Meia Praia, o qual demonstrou situações de ocupação do solo de forma desordenada e gananciosa, notadamente na última década, sob o ponto de vista do imobiliário turístico, como citam os estudos de Silva \& Ferreira (2011), Silva \& Soriano-Sierra (2013; 2015) e Silva (2013). Em contraponto, após o processo de intervenção na orla com obras de ordenamento e revitalização, oriundos do Projeto Orla no trecho da orla do bairro Meia Praia, o município sofreu transformações socioespaciais significativas, impactando de forma positiva a cidade, o bairro, seus moradores e visitantes. Entre essas alterações, houve a mudança de percepção dos 
atores sociais sobre o espaço, os quais descreviam a orla marítima como um ambiente inóspito e, atualmente, sentem-se com a autoestima elevada frente às transformações urbanas e ambientais ocorridas na orla, considerando-a um ambiente aprazível de convivência social (Silva \& Soriano-Sierra, 2013; 2015; Silva, 2013).

Cabe ressaltar a relevância do estudo, em apresentar um diagnóstico sob a forma de depoimentos sobre o processo de implementação do Projeto Orla em uma cidade costeira e turística, apresentando seus pontos positivos e limitações, a partir da experiência dos protagonistas do processo - a gestão pública.

Por conseguinte, o objetivo do estudo foi descrever o processo de implementação do Projeto Orla em Itapema - Santa Catarina, segundo os gestores públicos municipais, na perspectiva de compartilhar as experiências obtidas e a sistematização do processo.

\section{Procedimentos metodológicos}

O estudo enquadra-se no paradigma interpretativista que, segundo Leite (2008, p. 100), "[...] possui o poder de analisar os fenômenos com consideração de contexto". Com relação aos objetivos, a pesquisa apresenta-se como exploratória e descritiva (Gil, 2012), que, neste caso, apresenta-se como a descrição do processo de implementação do Projeto Orla no município de Itapema (SC).

Nesta investigação, adotou-se o método estudo de caso, pois esse elucida a "descrição e análise de uma simples entidade, fenômeno ou unidade social" (Merriam, 1998, p. 16; Yin, 2005). Somam-se a este a pesquisa bibliográfica realizada em bases de dados eletrônicas, cujo objetivo foi buscar estudos similares e demais publicações inerentes ao assunto; a observação simples do campo de estudo, neste caso, a orla do bairro Meia Praia (Gil, 2012); e a pesquisa documental realizada em fontes disponíveis na Prefeitura Municipal de Itapema, Santa Catarina.

\subsection{Coleta de dados}

A fase de coleta de dados foi conduzida em duas etapas: a primeira realizou-se por meio da técnica de entrevista semiestruturada com os representantes da gestão pública municipal, sendo o roteiro de entrevista elaborado com perguntas abertas, possibilitando ao entrevistado discorrer sobre o assunto proposto. Para a seleção dos participantes, utilizou-se a amostragem não probabilística, cuja classificação se baseou na amostragem intencional (Miguel, 1970; Gil, 2012). Desses, três atuavam no poder executivo municipal na gestão 2006-2012 e uma quarta informante atuava como representante do Projeto Orla na SPU, na esfera estadual. Logo, foram entrevistados quatro stakeholders entre $17 \mathrm{e}$ 29 de março de 2013, todos participantes diretamente do processo de implementação do Projeto Orla em Itapema. Como atributo da técnica de entrevista semiestruturada, foram feitos registros de áudio das entrevistas e transcritos para confiabilidade do estudo, além de ter sido adotado o "Termo de Consentimento Livre e Esclarecido", visando à plena concordância do entrevistado e à garantia do anonimato.

A segunda etapa ateve-se à observação do campo, ou seja, da zona costeira municipal, especialmente no trecho da orla do bairro Meia Praia e do Parque Linear Calçadão - principal obra de revitalização realizada. O registro das observações foi feito mediante caderno de notas e fotografias e foram posteriormente cotejadas com os resultados das entrevistas. 


\subsection{Interpretação e análise dos dados qualitativos}

A unidade de análise (do caso) para o problema de pesquisa foi a orla do bairro Meia Praia. O método adotado para análise dos dados está baseado na "construção da explanação", que consiste em um tipo especial de adequação padrão. Seu objetivo, segundo Yin (1982), é analisar os dados do estudo de caso construindo uma explanação sobre ele. Assim, a explanação consistiu sobre o processo de implementação do Projeto Orla no município de Itapema (SC), a partir dos resultados das entrevistas realizadas com os stakeholders.

\section{Caracterização da área de estudo}

O município de Itapema está localizado no litoral centro-norte do Estado de Santa Catarina, a $60 \mathrm{~km}$ da capital do Estado, Florianópolis, com área territorial de $57,803 \mathrm{~km}^{2}$, apresentando os seguintes municípios limítrofes: Balneário Camboriú ao norte, Porto Belo ao sul e Camboriú a oeste, latitude $27^{\circ} 05^{\prime} 25^{\prime \prime}$ 'S e longitude $48^{\circ} 36^{\prime} 41^{\prime \prime} \mathrm{W}$ (Figura 1):

O município é cortado de norte a sul pela Rodovia Federal BR-101, resultando parcialmente no crescimento demográfico que apresenta nas últimas décadas. Segundo dados do Instituto Brasileiro de Geografia e Estatística (IBGE, 2010), sua população fixa é de 45.797 habitantes, embora o número de residentes venha crescendo anualmente, com uma população estimada em 57.089 para o ano de 2015 (IBGE, 2015). A população flutuante, considerada por visitantes temporários, chegou ao ápice na temporada de verão de 2012/2013, com aproximadamente 600 mil habitantes.

Itapema, assim como outras cidades litorâneas, teve no turismo sua fonte geradora de recursos a partir da década de 1970, aumentando consideravelmente a oferta de segundas residências para o aproveitamento do período de férias, assim como foi notável o crescimento do comércio de bens e ser-

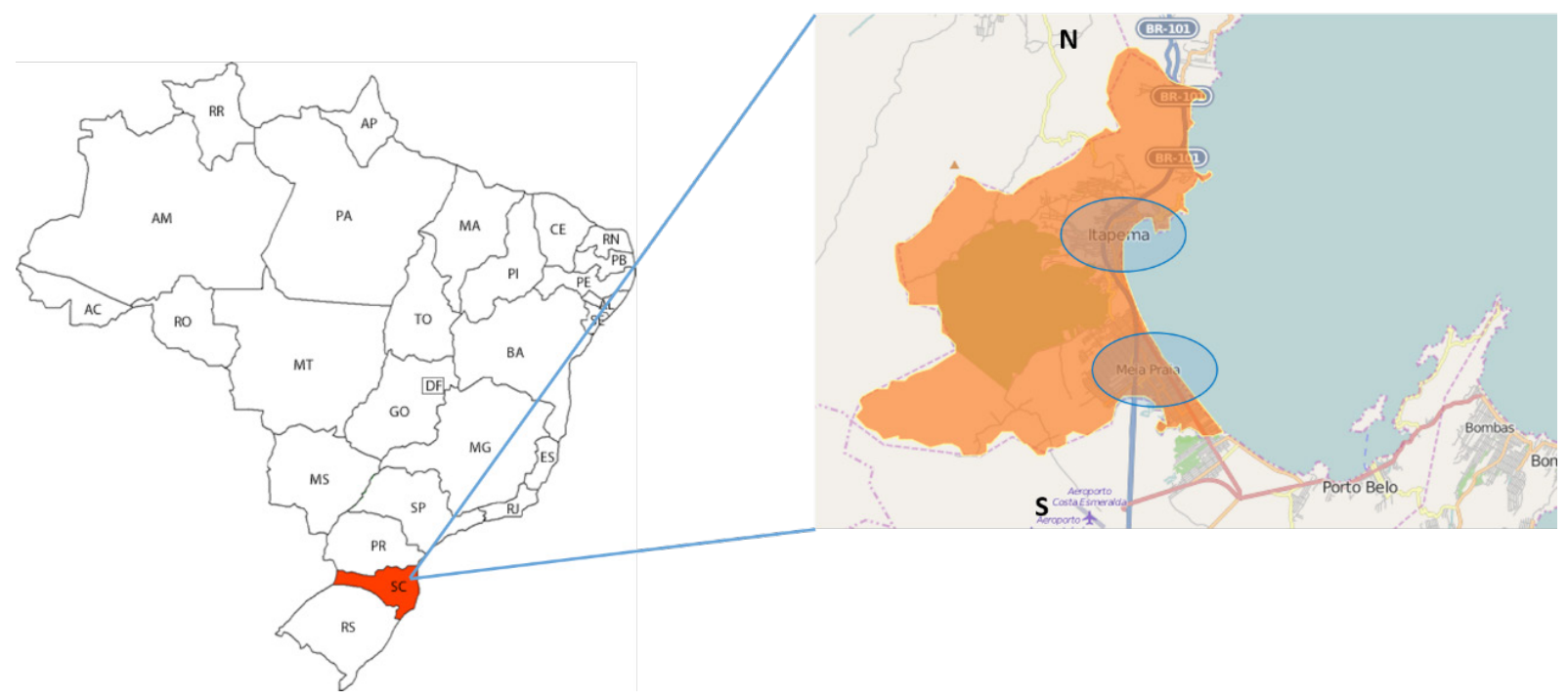

FIGURA 1 - Localização geográfica de Itapema no Estado de Santa Catarina. FONTE: Adaptado de Instituto Brasileiro de Geografia e Estatística (2015). 
viços para atendimento ao visitante (Nemetz, 2004). Por isso, o setor de serviços, incluindo o turismo, é o segmento econômico com maior incidência de impostos e geração de emprego e renda. Após este período histórico, o turismo gerou a expansão da construção civil e, por consequência, do setor imobiliário, elevando o município à posição de segundo polo regional no setor, perdendo na microrregião da Associação dos Municípios da Foz do Rio Itajaí (AMFRI) apenas para Balneário Camboriú (Do Amaral Pereira et al., 2002).

Segundo Silva (2013, p. 103), ao longo da história houve desigualdades entre as áreas leste e oeste da cidade, "onde a região litorânea a leste é mais ocupada, desenvolvida e impactada ambientalmente que a parte oeste". Além disso, é notável a incidência do adensamento populacional nesta faixa territorial, devido à proximidade da costa litorânea, motivo principal de visitação ao município, o qual propicia o interesse dos veranistas em adquirir imóveis na orla, fomentando as construções multifamiliares e os impactos antrópicos na paisagem. Este fato acelerou o crescimento demográfico e imobiliário do município e, em muitos dos seus espaços, é possível verificar saturação.

O aumento vertiginoso da população flutuante implica em inúmeras problemáticas de ordem estrutural urbana, como a ineficiência do sistema de tratamento de esgoto, a capacidade de abastecimento de água, intensa produção de lixo, poluição estética e sanitária, etc., devido ao número expressivo de pessoas alocadas num mesmo espaço e tempo, além de apontar vulnerabilidade da orla em face de processos naturais, com erosão e desmatamentos (Silva, 2013). Vislumbra-se que a saturação urbana, principalmente na faixa costeira, ocorreu sem freio, sem planejamento sustentável e sem a participação cidadã que deveria inserir-se à elaboração e atualização do Plano Diretor, que no período de 2002 a 2013 estava desatualizado, contrariando os princípios do Estatuto da Cidade (Lei n ${ }^{\circ}$ 10.257/2001) (Brasil, 2002).

Itapema apresenta $14 \mathrm{~km}$ de orla marítima linear, composta por quatro praias: a praia da Mata de Camboriú; a praia da Ilhota; a praia do Cabeço ou Grossa e a praia de Itapema, a qual é dividida em Canto da Praia, praia central de Itapema e Meia Praia (IBGE, 1991). Silva (2013) explica que Meia Praia é o bairro que possui a melhor infraestrutura de serviços, caracterizando-se pelos equipamentos e serviços turísticos que dispõe, como bares, restaurantes, hotéis, comércio e outros, sendo também o espaço com a maior quantidade de alvarás para construções de edifícios no município.

Os maiores atrativos turísticos de Meia Praia são a orla e a praia, com uma extensão de $5 \mathrm{~km}$. Contudo, como consequência do adensamento populacional, o bairro está passando por um acelerado processo de verticalização, com edifícios de alto padrão e, consequentemente, especulação imobiliária, processo que vem a comprometer a qualidade de vida da população local, com alterações na paisagem e deflorestamento da vegetação de restinga, que tem por função manter o equilíbrio morfodinâmico do mar e da terra, impedindo a invasão das marés (Silva, 2013).

Com base neste cenário, no intuito de tornar a cidade e o espaço costeiro mais aprazível e ordenado, com respeito às leis de proteção aos recursos costeiros e marinhos, a gestão pública deu início em 2006 ao processo de implementação do Projeto Orla, obtendo como um dos resultados efetivos a implantação do "Parque Linear Calçadão", cujo objetivo foi o de revitalizar e humanizar a orla marítima, em uma perspectiva sustentável. 


\section{Resultados e discussão}

Os resultados denotam uma interpretação qualitativa sobre a intervenção pública realizada na orla do bairro Meia Praia - Itapema, como resultado prático do Projeto Orla.

A decisão da gestão pública de Itapema em intervir na orla marítima com obras de revitalização teve início no ano de 2006, motivada por diversos impactos ambientais apurados pela Prefeitura Municipal na orla, especialmente no bairro Meia Praia. Os impactos foram gerados por construções desordenadas, decorrentes da ausência de fiscalização e intervenções irregulares e desastrosas como, por exemplo, esgoto a céu aberto, resíduos de construção civil e equipamentos de terraplanagem sobrepostos na praia, cordão de dunas e vegetação praticamente ausentes, altos índices de poluição estética, sanitária e visual e a privatização da praia pelos proprietários de imóveis localizados à beira-mar, como ilustra a Figura 2.
Esse cenário instigou a gestão pública municipal a definir soluções para contrapor a realidade ora apresentada. Com este propósito, em 2007, o poder executivo municipal retomou o processo de implementação do Projeto Orla, concomitantemente à incumbência de cumprir um Termo de Ajuste de Conduta (TAC) a fim de resolver os problemas e danos ambientais causados e recorrentes na orla municipal por gestões anteriores.

Assim, membros do poder executivo apresentaram ao Ministério Público Federal, por meio da Procuradoria Pública do Município de Itajaí, o Estudo de Impacto Ambiental (EIA-RIMA) sugerindo a implantação de um parque linear no formato "calçadão", composto de ciclovia e mobiliários urbanísticos, que garantisse a acessibilidade e a valorização das pessoas, numa necessidade urgente de organizar o espaço costeiro local. Além disso, buscava-se tornar o turismo uma atividade aprazível para a comunidade local, assim como para os visitantes, e não uma atividade de desordem e degradação ambiental como outrora se apresentava.
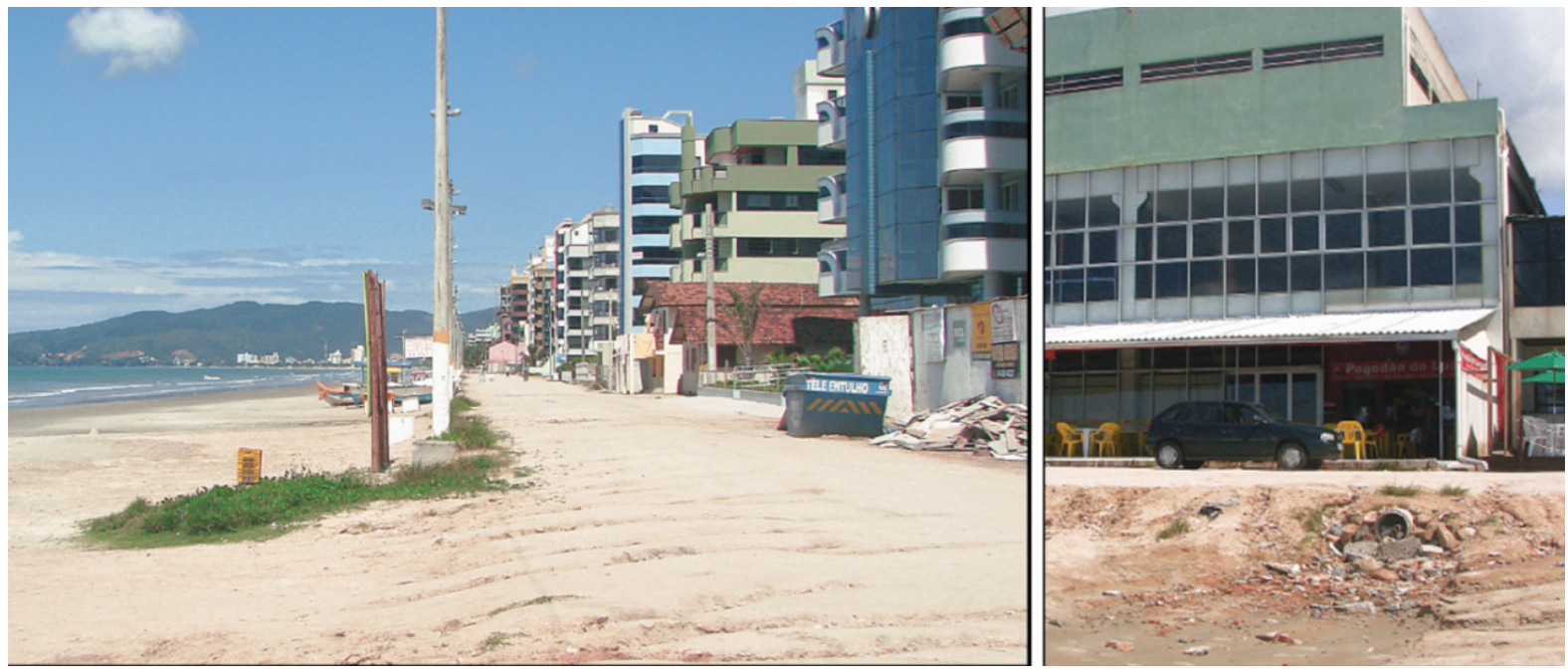

FIGURA 2 - Orla do bairro Meia Praia anterior ao Parque Linear Calçadão.

FONTE: Revista Parque Calçadão (2011). 
No mesmo ano, o município requereu junto à GRPU, em Santa Catarina, a cessão de uso de área de domínio da União - como prevê o Decreto Federal n. 3.725, de 10 de janeiro de 2001, que regulamenta a Lei n. 9.636, de 15 de maio de 1998, com área de $70.792,93 \mathrm{~m}^{2}$, perfazendo um perímetro total de 7.525,75 m, localizada no bairro Meia Praia, com a finalidade de implantação do Parque Linear, prevendo construção de ciclovia e passeio público, implantação de áreas arborizadas, equipamentos de lazer e quiosques (Brasil, 2001; Ministério Público Federal, 2007; Silva, 2013) (Figura 3):

O contrato de cessão de urso permite a exploração da orla para reorganização do espaço costeiro municipal, cujo objetivo é a atuação descentralizada, incluindo a recuperação da vegetação, assim como é requisito obrigatório para dar prosseguimento ao processo de implementação do Projeto Orla, garantindo a celebração de convênios, inclusive o de cooperação técnica com a SPU, por meio da GRPU, como parte dos procedimentos para a descentralização da gestão da orla (Brasil, 2005; Silva, 2013).

Como preveem os requisitos legais para a descentralização da orla e a inserção do município no Projeto Orla, várias foram as etapas que o poder executivo municipal necessitou cumprir. Dentre essas, esteve o Plano de Gestão Integrada da Orla (PGI). Seu conteúdo versa sobre a promoção da gestão sustentável da orla do município por meio de intervenções gradativas, devendo explicitar, entre outras ações, o cronograma definido para as obras na orla, sua base legal e as ações definidas para cada trecho da orla. Segundo o MMA e a SPU, esse documento está previsto como atribuição específica da Coordenação Municipal do Projeto Orla, sendo também obrigatório para a continuidade do processo (Brasil, 2005).

Para a construção do PGI, foram realizadas várias ações, ou seja, etapas a serem cumpridas para a implementação do Projeto Orla. A primeira delas foi o Seminário de Mobilização do Projeto Orla para conhecimento e apreciação da comunidade local, realizado em 22 e 23 de junho de 2007, além da realização de oficinas e levantamentos técnicos de toda a orla do município a fim de estimar perspectivas

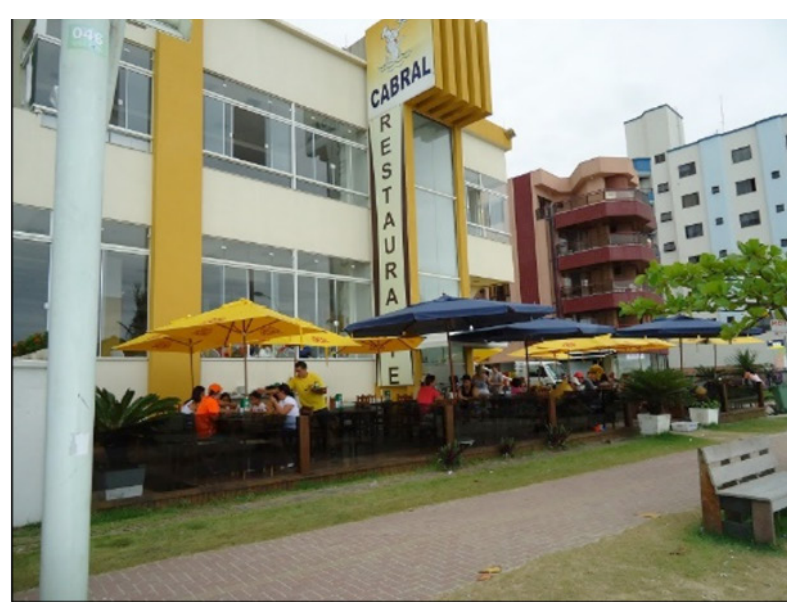

FIGURA 3 - Ciclofaixa e estabelecimento de alimentação no Parque Linear Calçadão. FONTE: Os Autores, 2013. 
futuras desejadas, e ainda a constituição do Comitê Gestor da Orla, que consiste em "um núcleo de articulação e deliberação em nível local, especialmente junto aos diferentes atores e à sociedade. [...], cuja responsabilidade é apoiar as decisões e fiscalizá-las durante e após o processo de intervenção na orla" (Brasil, 2005, p. 17).

Houve também a participação cidadã, por meio de audiência pública, tendo por objetivo apresentar os estudos realizados e ouvir a comunidade sobre a melhor forma de revitalização da orla do "trecho Meia Praia", sendo o primeiro local a ser contemplado pelo projeto devido às suas características socioeconômicas e de relevância para $\mathrm{o}$ turismo. Políticas públicas, a exemplo do Projeto Orla, possuem em comum a exigência da participação cidadã na implementação de seus instrumentos e nos processos de tomada de decisão (Viana et al., 2012). Scherer (2013, p. 8) complementa, ao afirmar que o Projeto Orla é o "único instrumento do Programa Nacional de Gerenciamento Costeiro que realmente determina qual o grau e como se dá a participação popular no processo de gestão".

$\mathrm{Na}$ audiência realizada em 22 de agosto de 2008, participaram aproximadamente 650 pessoas (Silva, 2013). Após a apresentação das alternativas para a revitalização da orla, contempladas em: a) reestruturação sem intervenção na forma original; b) avenida beira-mar com pista de rolamento; e, c) parque linear segundo a proposta do EIA-RIMA, foram propostas duas formas de votação, sendo uma por aclamação e outra por sufrágio secreto. Das 650 pessoas presentes, $96 \%$ votaram, por sufrágio secreto, pela terceira alternativa - Parque Calçadão, enquanto que, por aclamação, a terceira alternativa foi aclamada por unanimidade, manifestando a decisão da sociedade e também do projeto EIA-RIMA.
Viana et al. (2012, p. 359) expõem que a gestão participativa:

É fundamental em um processo dessa natureza, uma vez que favorece consenso entre conflitos, diálogo institucional, transparência legal e justificativa técnica e científica num espaço de discussão aberto para a sociedade, além de dar voz à comunidade que vive o dia a dia do local.

A gestão participativa é considerada vital para a implementação de projetos e ações que atingem o coração de uma cidade como, por exemplo, sua orla marítima. Sobre esse aspecto, Cardoso Junior et al. (2012) relatam que no processo de intervenção do Projeto Orla na Praia da Tartaruga, em Búzios (RJ), verificou-se que a participação e o aval da população envolvida no processo promoveram maior aceitação e atuação nas decisões de intervenção locais.

Contudo, mesmo seguindo as orientações dos técnicos da GRPU/SC, algumas das etapas supracitadas não tiveram efetividade e continuidade, a exemplo do Comitê Gestor da Orla, que não foi implementado por ato normativo municipal e, por isso, o grupo inicialmente constituído ficou desarticulado e tornou-se inoperante no processo. De acordo com representantes do bairro Centro de Itapema, "o Comitê Gestor da Orla estava bem dinâmico, muito atuante, as cobranças estavam sendo muito altas e, talvez por isso, não houvesse vontade política para ajudar" 1 .

Portanto, para o município de Itapema, a metodologia do Projeto Orla foi parcialmente adotada para sua implementação. Segundo a instrutora do Projeto Orla - representante da GRPU - e o técnico da Fundação Ambiental Área Costeira de Itapema (FAACI), os passos para a efetivação do projeto são descritos a seguir, com algumas carências: 
Contrato formalizado de cessão de uso de área da União; visitas técnicas a campo; elaboração do dossiê de documentos do município; oficinas de capacitação para os instrutores locais; realização de audiência pública para definição da forma de intervenção na orla.

Além disso, a legislação federal correspondente ao assunto foi lida e estudada pelos técnicos e demais membros do Comitê Gestor da Orla (no municipio grupo de trabalho), assim como a legislação municipal. Entretanto, ficou pendente o Plano de Gestão Integrada (PGI), pois ele não foi concluído na sua totalidade e, também, o Comitê Gestor da Orla. Logo, não foram adotados todos os fundamentos e orientações do Projeto Orla. Faltaram coisas a fazer. (grifo dos autores) ${ }^{2}$

Verifica-se, de forma evidente, que muitas das ações não efetivadas pelo Projeto Orla nas cidades costeiras são recorrentes, como debatido no II Seminário Nacional para Avaliação do Projeto Orla em 2008 - Salvador (BA) (Cardoso Junior et al., 2012). A esse respeito, Cardoso Junior et al. (2012, p. 14) citam alguns deles, que vêm confirmar as mesmas problemáticas observadas em Itapema: a) a população não tem conhecimento dos PGI's, b) descontinuidade na implementação do Projeto Orla nos municípios, c) a maioria dos PGI's não teve suas ações implementadas, d) falta de recursos financeiros específicos para a implementação das ações previstas nos PGI's, entre outras.

Oliveira e Nicolodi (2012) elucidam que o Projeto Orla ainda apresenta problemas específicos, como os apontados neste estudo, principalmente na implementação das ações definidas pelos Planos de Gestão. Contudo, segundo os autores, ele pode ser considerado uma ação governamental bem-sucedida para a gestão sustentável da orla, pois "trata-se de um projeto consolidado, com metodologia validada e amplamente aplicada ao longo de seus dez anos de existência" (Oliveira \& Nicolodi, 2012, p. 97).
O Parque Linear Calçadão (PLC) foi um dos resultados consolidados do processo de implementação do Projeto Orla em Itapema, sendo ele projetado segundo a percepção e conhecimento das pessoas que participaram das reuniões de trabalho, representantes do IBAMA, da FATMA, da GRPU e da empresa responsável pelo EIA-RIMA. A equipe, durante seu desenvolvimento, definiu diretrizes específicas quanto a geometria, circulação, equipamentos e paginação de passeio, com o seguinte programa de necessidades: ciclovia com sinalização para pedestres e ciclistas; calçadão construído com pavers ao invés de asfalto; paisagismo em torno dos edifícios multifamiliares e comerciais; faixa de arborização; recuperação da vegetação de restinga com telas de proteção e replantio de árvores nativas; instalação de equipamentos de lazer e recreação; postos salva-vidas; drenagem pluvial; implantação de mobiliário urbano ecológico; decks de madeira para acesso à praia com rampas para portadores de necessidades físicas; e iluminação fotovoltaica em toda a faixa da orla (Silva, 2013), como demonstra a Figura 4.

Parte do processo de implementação do Projeto Orla e implantação do Parque Linear Calçadão para o bairro Meia Praia em Itapema foi realizado em um período de seis anos. Havia intenção do Gestor Público Municipal em dar continuidade ao Projeto Orla nas demais extensões de orla do município, entretanto, a equipe pertencente à gestão 2006-2012 encerrou suas atividades ao final do ano de 2012, em função da conclusão do mandato. $\mathrm{Na}$ atual gestão, não se tem conhecimento sobre o prosseguimento do processo, mesmo com a retomada de diálogo por parte da GRPU nos anos de 2013 e 2014. Este fato confirma novamente um dos problemas da gestão pública local, como expõem Cardoso Junior et al. (2012).

\footnotetext{
2 Entrevistas concedidas em junho de 2013.
} 


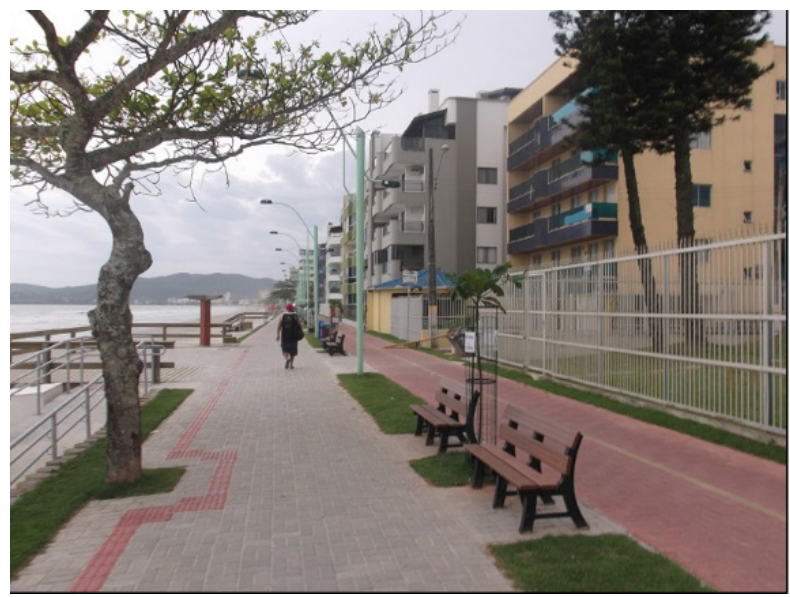

FIGURA 4 - Parque Linear Calçadão no bairro Meia Praia. FONTE: Os Autores (2013).

O que se percebe visivelmente é ausência de manutenção dos equipamentos instalados e insegurança no Parque Linear Calçadão, já que não há policiamento permanente no local e nenhum tipo de fiscalização do ambiente. Contudo, ao final do ano de 2014, o poder executivo municipal implantou quiosques para salva-vidas com banheiros para uso dos veranistas e demais frequentadores do calçadão.

Um exemplo do processo de implementação do Projeto Orla com algumas limitações significativas de ordem política é o município de Búzios (RJ), citados por Cardoso Junior et al. (2012). Segundo os autores, as ações do poder público municipal são exclusivamente de remediação e não preventivas no tocante ao gerenciamento costeiro, reduzindo seu caráter de planejamento.

Sobre este aspecto, Oliveira \& Nicolodi (2012), ao estudar várias cidades costeiras que estão em processo de implementação, destacam as principais dificuldades enfrentadas para a implementação dos PGI's, como a carência de recursos humanos e falta de disponibilidade de recursos financeiros nos municípios. No caso de Itapema, segundo o gestor

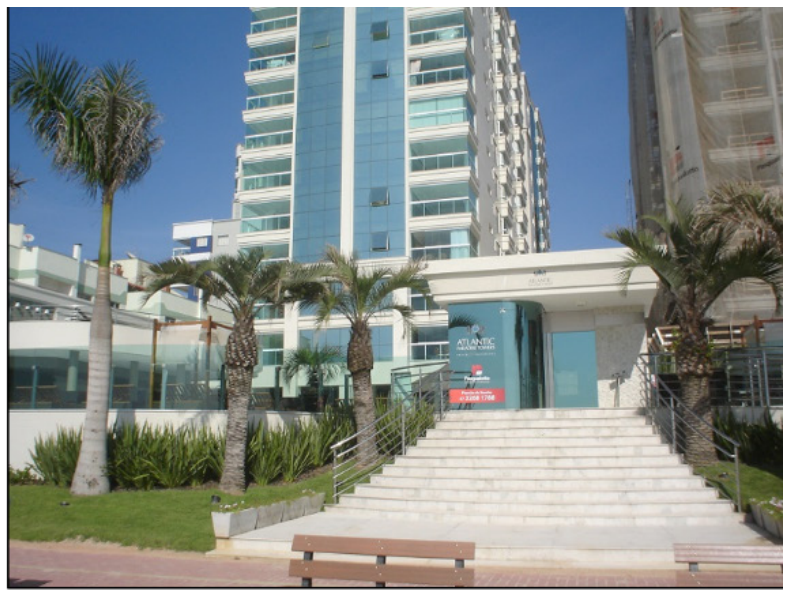

público, não houve previsão orçamentária para a manutenção dos equipamentos e demais mobiliários urbanísticos instalados no calçadão, culminando, em partes, no descontentamento da população local.

Portz et al. (2011), ao investigarem ferramentas de gestão ambiental para a zona costeira do Estado do Rio Grande do Sul, evidenciaram que até o ano de 2011 nenhum município havia assinado o convênio com o MMA e a SPU para adesão ao Projeto Orla. Ainda segundo suas considerações, o poder público municipal ainda não conseguiu colocar em prática os instrumentos de gestão, principalmente por falta de recursos, além da contratação de fiscais necessários para controlar as atividades, o que demonstra que muitos Estados ainda estão engatinhando na gestão integrada da zona costeira.

O processo de implementação do Projeto Orla em Itapema, ainda que apresente problemas de gestão com sobreposição de competências, gerou contentamento por parte dos moradores e visitantes, como confirmaram os resultados das pesquisas de percepção ambiental de Silva \& Soriano-Sierra (2013; 2015). Além disso, em maio do ano de 2009, o então Parque Linear Calçadão foi destaque na- 
cional em Planejamento Urbanístico e Paisagístico pelo Instituto Ambiental Biosfera, com o apoio da Universidade Federal do Rio de Janeiro e do Governo Federal. Em fevereiro de 2011, a cidade foi eleita pelo Grupo RBS como a segunda melhor infraestrutura turística entre as praias do Estado de Santa Catarina e a melhor do litoral norte, perdendo apenas para Jurerê Internacional, em Florianópolis (SC) (Prefeitura Municipal de Itapema, 2012, citado por Silva, 2013).

Finalmente, o Parque Linear Calçadão, como resultado prático do Projeto Orla em Itapema, pode ser considerado um exemplo de benchmarking em relação ao seu projeto urbanístico e de recuperação ambiental, como efeito do processo de intervenção e de participação da comunidade nas decisões de reorganização da orla.

\section{Considerações finais}

Tem-se verificado, ao longo dos anos, uma expansão do espaço urbano sem planejamento, muitas vezes caótico, com excessivas edificações, loteamentos em áreas de proteção permanente e terras da União, sem que haja atuação ostensiva dos órgãos de fiscalização ambiental e patrimonial. As teorias sobre gestão da sustentabilidade e cidades sustentáveis apontam que as cidades devem valorizar sua comunidade e seu espaço físico, não deixando se perder os vínculos de sociabilidade, assim como não colocar em risco a manutenção dos ecossistemas existentes e a sua biodiversidade.

No contexto da trama urbana, o Projeto Orla insere-se como um instrumento de planejamento da orla marítima, que inclui um amálgama de conflitos e interesses, pois a zona costeira contribui substancialmente para a manutenção da biodiversidade e se torna, com o passar dos anos, chamariz para investidores sobre este espaço na atualidade.
Dentre as questões que incutiram a pesquisa, buscou-se conhecer a trajetória e o processo legal de implementação do Projeto Orla no município de Itapema (SC). Ao comparar os depoimentos dos stakeholders com os manuais de orientação para a implementação do Projeto Orla em conjunto à sua base legal, verificou-se falhas de ordem técnica e gerencial por parte do executivo municipal. Em Itapema, o Projeto Orla não se efetivou inteiramente, segundo as diretrizes do MMA e SPU. Um exemplo refere-se à não efetivação do Plano de Gestão Integrada da Orla (PGI), o qual não foi legitimado pela comunidade local, sendo considerado obrigatório para adesão ao projeto. Além disso, verificou-se no próprio documento (PGI) a ausência de detalhamento do diagnóstico paisagístico da orla - essencial para projetar as ações presentes e futuras para o planejamento da orla municipal.

Outra atribuição recomendada pela Coordenação Nacional e Estadual do Projeto Orla, e que também não se efetivou, foi o Comitê Gestor da Orla, que visa à fiscalização dos projetos de intervenção. Em Itapema, ele foi instituído nos anos de 2007-2008, mas também não foi concretizado legalmente por ato normativo municipal (Silva, 2013). Portanto, compreende-se que tanto o PGI como o Comitê Gestor da Orla, além de constituírem etapas mandatórias para a celebração do convênio de cooperação técnica com a SPU/GRPU, como parte dos procedimentos de descentralização da orla (Brasil, 2005), são formados por pessoas-chave que têm conhecimento, comprometimento e envolvimento com as ações previstas para o planejamento e a manutenção das estruturas a serem construídas no espaço da orla, devendo, inclusive, participar ativamente das decisões do Plano Diretor Municipal, o que de fato não ocorreu.

Mesmo com as exigências não cumpridas, o município celebrou o convênio, recebeu as orienta- 
ções e recursos das esferas federal e estadual para a implantação do Parque Linear Calçadão que, após concluído, mostrou-se aprazível à comunidade local e aos visitantes, sendo considerada uma obra de intervenção pública sustentável, como demonstram os resultados das pesquisas de Silva \& Soriano-Sierra $(2013 ; 2015)$ e as premiações obtidas.

O Projeto Orla aborda uma série de diretrizes norteadoras para a descentralização da orla, preconizando princípios sustentáveis, cabendo aos Estados e Municípios seguir suas orientações, prevendo, por exemplo, revitalização do espaço, manutenção de suas características físicas e biológicas e uma gestão ambiental eficiente.

No estudo de caso realizado em Itapema, no tocante ao cumprimento das diretrizes do Projeto Orla, verificou-se a necessidade de instituir instrumentos de avaliação e verificação das obras executadas pelo poder executivo municipal, pelos munícipes e sociedade civil organizada, além de prever dotação orçamentária para a manutenção das estruturas instaladas. Além disso, indica-se como fundamental a validação dos projetos por parte da comunidade e stakeholders, com o apontamento de problemas existentes e originados, e a indicação de sugestões de melhorias - papel este concernente também ao Comitê Gestor da Orla. Tais sugestões vão ao encontro das limitações encontradas nos estudos de Cardoso Junior et al. (2012) sobre o processo de implementação do Projeto Orla em Búzios (RJ).

Finalmente, os objetivos do estudo foram alcançados, na perspectiva de conhecer as etapas que um município necessita ao implementar o Projeto Orla, mas que nem sempre todos os procedimentos técnicos são concretizados. No estudo, ficaram evidentes as limitações da equipe técnica e de ge- renciamento do Projeto Orla nas esferas estadual e municipal na condução de fases do projeto, os benefícios sociais e ambientais para o espaço praial e para a população, assim como a importância do Projeto Orla como uma política nacional construída de forma compartilhada com outros entes federados e com a sociedade civil.

Outro ponto importante a destacar no desenvolvimento da pesquisa foi a limitação de publicações científicas que descrevessem o diagnóstico do processo de implementação do Projeto Orla em cidades costeiras do Brasil, o que valida a realização dessa investigação. Por fim, percebeu-se, na pesquisa bibliográfica realizada em bases de dados, poucos estudos descritivos relatando diagnósticos, sendo que, em sua maioria, os resultados não são sistematizados e completos, a partir de uma perspectiva abrangente e setorial.

Sugere-se, como aprofundamento da pesquisa, analisar outras cidades costeiras que tenham implementado parte ou todo o Projeto Orla em suas extensões de orla, a fim de proceder a comparações e verificar as principais limitações e oportunidades geradas em relação à gestão sustentável da orla marítima, culminando em novos estudos e gerando conhecimento científico para melhorar e atualizar as diretrizes do Projeto Orla e outros instrumentos da gestão costeira. Além disso, recomenda-se sistematizar, compartilhar e aplicar o conhecimento gerado em relação à implementação do Projeto Orla num processo de benchmarking, de modo que outras cidades com realidades semelhantes possam se espelhar neste estudo de caso (Itapema), assim como em outras experiências, aproveitando os pontos positivos destacados e evitando os negativos já comprovados. 


\section{Referências}

Brasil. Lei $n^{\circ} 7.661$, de 16 de maio de 1988. Institui o Plano Nacional de Gerenciamento Costeiro. Brasília, DOU de 18/05/1988.

Brasil. Constituição da República Federativa do Brasil, de 5 de outubro de 1988. 11. ed. São Paulo: Atlas, 1998.

Brasil. Decreto $n^{\circ} 3.725$, de 10 de janeiro de 2001. Regulamenta a Lei $\mathrm{n}^{\circ}$ 9.636, de 15 de maio de 1998, que dispõe sobre a regularização, administração, aforamento e alienação de bens imóveis de domínio da União, e dá outras providências. Brasília, DOU de 11/01/2001.

Brasil. Lei $n^{\circ}$ 10.257, de 10 de julho de 2001. Estatuto da Cidade e Legislação Correlata. 2. ed., atual. Brasília: Senado Federal, Subsecretaria de Edições Técnicas, 2002.

Brasil. Decreto-lei $n^{\circ}$ 5.300, de 7 de dezembro de 2004. Regulamenta a Lei $\mathrm{n}^{\circ} 7.661$, de 16 de maio de 1988, que institui o Plano Nacional de Gerenciamento Costeiro - PNGC, dispõe sobre regras de uso e ocupação da zona costeira e estabelece critérios de gestão da orla marítima, e dá outras providências. Brasília, DOU de 7/12/2004.

Brasil. Ministério do Meio Ambiente. Projeto Orla: guia de implementação. Secretaria de Qualidade Ambiental; Ministério do Planejamento, Orçamento e Gestão, Secretaria do Patrimônio da União, Brasília, DF, Brasil, 2005.

Brasil. Ministério do Meio Ambiente. Projeto Orla: fundamentos para Gestão Integrada. Secretaria de Qualidade Ambiental; Ministério do Planejamento, Orçamento e Gestão, Secretaria do Patrimônio da União, Brasília, DF, Brasil, 2006.

Brorström, S. Strategizing sustainability: The case of River City, Gothenburg. Cities, 42 25-30, 2015. doi: 10.1016/j. cities.2014.08.005

Claro, P. B. de O.; Claro, D. P.; Amâncio, R. Entenda o conceito de sustentabilidade nas organizações. Revista de Administração, 43(4), 289-300, 2008.

Cardoso Jr., R. A. F.; Caiuby, G.; Obraczka, M.; Magrini, A. Projeto Orla: proposta para maior sustentabilidade e eficiência no gerenciamento costeiro - Armação de Búzios (RJ). Sistemas \& Gestão, 6(3), 347-365, 2012. Disponível em: <http://www.revistasg.uff.br/index.php/sg/article/ viewArticle/V6N3A8>.
CONAMA - Conselho Nacional do Meio Ambiente. Resolução n. 341, de 25 de setembro de 2003. Disponível em: $<$ http://www.mma.gov.br/port/conama/res/res03/res34103. $\mathrm{xml}>$.

Do Amaral Pereira, R. M. F.; De Oliveira, R. A.; Westerlon, D. O turismo e a dinâmica socioespacial do município de Itapema. Turismo: visão e ação, 4(9), 61-74, 2002.

Francia, J. A. B. Ocupación del territorio litoral en ciudades turísticas de México. Revista Bitácora Urbano Territorial, 20(1), 41-52, 2012. Disponível em: <http://www.redalyc. org/articulo.oa? $\mathrm{id}=74824041005>$.

Gil, A. C. Métodos e técnicas de pesquisa social. 6. ed. São Paulo: Atlas, 2012.

IBGE - Instituto Brasileiro de Geografia e Estatística. Classificação da vegetação brasileira, adaptada a um sistema universal. Departamento de Recursos Naturais e Estudos Ambientais. Rio de Janeiro: IBGE, 1991. 123p.

IBGE - Instituto Brasileiro de Geografia e Estatística. Indicadores sociais municipais: uma análise dos resultados do universo do Censo Demográfico 2010. Disponível em: $<$ http://www.ibge.gov.br/cidadesat/link. php? codmun $=420830>$.

IBGE - Instituto Brasileiro de Geografia e Estatística. Cidades@. População estimada de Itapema para 2015. Disponível em: <http://cidades.ibge.gov.br/xtras/perfil. php?lang=\& codmun=420830 $>$.

IBGE - Instituto Brasileiro de Geografia e Estatística. Cidades@2015. Infográficos Itapema. Disponível em: $<$ http://www.cidades.ibge.gov.br/painel/painel.php?lang $=\&$ codmun $=420830 \&$ search $=||$ infogr $\%$ E1 ficos:-dados-gerais-do-munic\%EDpio>.

Itapema (Município). Lei Complementar consolidada de Itapema/SC, $n^{\circ} 11 / 2002$ de 06 de fevereiro de 2002. Dispõe sobre o zoneamento e uso do solo do município de Itapema, cria o Conselho Municipal de Planejamento Urbano e dá outras providências.

Lanza, S.; Randazzo, G. Tourist-beach protection in northeastern Sicily (Italy). Journal of Coastal Conservation, 17, 49-57, 2013. doi: 10.1007/s11852-012-0217-0 
Leite, C; Awad J. di C. Cidades sustentáveis, cidades inteligentes: desenvolvimento sustentável num planeta urbano. Porto Alegre: Bookman, 2012.

Leite, F. T. Metodologia científica: métodos e técnicas de pesquisa (monografias, dissertações, teses e livros). 2. ed. Aparecida, SP: Ideias e Letras, 2008.

Lima, L. B. B. M. Impactos del turismo de sol y playa en el litoral sur de Sergipe, Brasil. Estudios y Perspectivas en

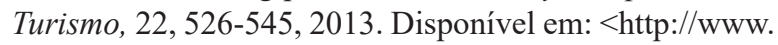
estudiosenturismo.com.ar/PDF/V22/N03/v22n3.pdf $>$.

Macedo, S. S. Paisagem, litoral e formas de urbanização. In: Projeto Orla: subsídios para um projeto de gestão. Ministério do Meio Ambiente, Secretaria de Qualidade Ambiental nos Assentamentos Humanos / Ministério do Planejamento, Orçamento e Gestão, Secretaria do Patrimônio da União, Brasília, DF, 2004. p. 45-64.

Merriam, S. B. Qualitative research and case study applications in education. San Francisco: Jossey-Bass, 1998.

Miguel, G. B. Métodos de pesquisa pedagógica. São Paulo: Loyola, 1970.

Ministério do Turismo. Turismo de sol e praia: orientações básicas. 2.ed. Brasília, DF: Ministério do Turismo, 2010. (Coleção Manual de Segmentação, onze volumes).

Ministério Público Federal. Procuradoria da República em Itajaí. Termo de Compromisso e Ajustamento de Conduta (TAC). Procedimento administrativo ambiental referente ao Estudo de Impacto Ambiental (EIA-RIMA) de Itapema. Itajaí, 2007.

Moraes, A. C. R. Contribuição para a gestão costeira do Brasil: elementos para uma geografia do litoral brasileiro. São Paulo: Annablume, 2007.

Moraes, A. C. R.; Zamboni, A. Construindo o conceito de orla marítima. In: Projeto Orla: subsídios para um projeto de gestão. Ministério do Meio Ambiente, Secretaria de Qualidade Ambiental nos Assentamentos Humanos / Ministério do Planejamento, Orçamento e Gestão, Secretaria do Patrimônio da União, Brasília, DF, Brasil, p. 7-11, 2004.

Nakano, K. (Coord.). Projeto Orla: implementação em territórios com urbanização consolidada. São Paulo: Instituto Polis; Brasília: Ministério do Planejamento, Orçamento e Gestão, 2006.
Nemetz, S. M. M. C. C. S. de. Balneabilidade de praias do litoral centro-norte de Santa Catarina: estudo de percepção ambiental. Blumenau, Dissertação (Mestrado em Engenharia Ambiental) - Universidade Regional de Blumenau, 2004.

Oliveira, M. R. L. de; Nicolodi, J. L. A gestão costeira no Brasil e os dez anos do Projeto Orla: uma análise sob a ótica do poder público. Journal of Integrated Coastal Zone Management, 12(1), 91-100, 2012. Disponível em: <http:// www.aprh.pt/rgci/pdf/rgci-308_Oliveira.pdf $>$.

Pinto, A. C. Projeto Orla: a implementação de uma política pública de gestão compartilhada entre os entes federativos, em áreas de domínio da união: o caso de Santa Catarina. Florianópolis, Monografia (Especialização em Gestão Pública) - Instituto Federal de Educação, Ciência e Tecnologia de Santa Catarina (IFSC), 2012.

Portz, L.; Manzolli, R. P.; Corrêa, I. C. S. Ferramentas de gestão ambiental aplicadas na zona costeira do Rio Grande do Sul, Brasil. Revista de Gestão Costeira Integrada, 11(4), 459-470, 2011. Disponível em: <http://www.aprh.pt/rgci/ pdf/rgci-278_Portz.pdf $>$.

Prefeitura Municipal de Itapema. Ministério do Planejamento, Orçamento e Gestão. Plano de gestão integrada da orla marítima do município de Itapema. Itapema, SC, 2007.

Prefeitura Municipal de Itapema. Revista Parque Calçadão. Itapema, 2011.

Sachs, I. Desenvolvimento: includente, sustentável, sustentado. Rio de Janeiro: Garamond, 2008.

Schaltegger, S. Sustainability as a Driver for Corporate Economic Success. Consequences for the Development of Sustainability Management Control. Society and Economy, 33(1), 15-28, 2011. doi: 10.1556/SocEc.33.2011.1.4

Scherer, M. Gestão de praias no Brasil: subsídios para uma reflexão. Journal of Integrated Coastal Zone Management, 1, 3-13, 2013. doi: 10.5894/rgci358

Seiffert, M. E. B. Gestão ambiental: instrumentos, esferas de ação e educação ambiental. 2. ed. São Paulo: Atlas, 2011.

Silva, A. F. C. da; Ferreira, A. L. O imobiliário-turístico e o Nordeste Brasileiro: dinâmicas econômicas e urbanas sobre o litoral. Revista Geográfica de América Central, 2(47), 1-15, 2011. Disponível em: <http://www.revistas.una.ac.cr/ index.php/geografica/article/view/3176>. 
Silva, M. E. M. da. Gestão sustentável da orla marítima em destinos turísticos costeiros: a percepção dos atores sociais. Florianópolis, Dissertação - (Mestrado em Engenharia e Gestão do Conhecimento) - Universidade Federal de Santa Catarina, 2013.

Silva, M. E. M. da; Soriano-Sierra, E. J. Gestión sustentable de la orla marítima en destinos turísticos: una perspectiva social sobre el proyecto ORLA. Estudios y Perspectivas en Turismo, 22, 805-827, 2013. Disponível em: <http:// www.estudiosenturismo.com.ar/PDF/V22/N05/v22n5a01. doc.pdf $>$.

Silva, M. M. da; Soriano-Sierra, E. J. Análise da percepção do visitante sobre a revitalização da orla marítima: o modelo do Parque Linear Calçadão, Itapema - Santa Catarina - Brasil. Revista Brasileira de Pesquisa em Turismo, 9(1), 76-96, 2015. doi: 10.7784/rbtur.v9i1.741

Starik, M.; Kanashiro, P. Toward a theory of sustainability management: uncovering and integrating the nearly obvious. Organization \& Environment, 26(1), 7-30, 2013. doi: $10.1177 / 1086026612474958$

Van Vuren, S.; Matthjis, K.; Jorissen, R. E. J. Coastal defense and societal activities in the coastal zone: Compatible or conflicting interests? Journal of Coastal Research, 20(2), 550-561, 2004. doi: 0.2112/1551-5036(2004)020[0550:CD ASAI]2.0.CO;2

Vianna, L. F. de N.; Bonetti, J.; Polette, M. Gestão costeira integrada: análise da compatibilidade entre os instrumentos de uma política pública para o desenvolvimento da maricultura e um plano de gerenciamento costeiro no Brasil. Journal of Integrated Coastal Zone Management, 12(3), 357-372, 2012. doi: 10.5894/rgci335

Yin, R. K. Studying the implementation of public programs. In: William, W. et al. (Eds.). Studying implementation: Methodological and administrative issues. Chatham, NJ: Chatham House, 1982. p. 36-72.

Yin, R. K. Estudo de caso: planejamento e métodos. 3. ed. Porto Alegre: Bookman, 2005. 